5. Dresner S, Codere F, Browstein S, Jouve P. Lacrimal drainage system inflammatory masses from retained silicone tubing. Am J Ophthalmol 1984;98:609.

6. McCormick SA, Lindberg JV. Pathology of nasolacrimal duct obstruction. In: Lindberg JV, editor. Lacrimal surgery.

London: Churchill Livingstone, 1988:169.

7. Welham RAN, Henderson PH. Results of dacryocystorhinostomy: analysis of causes for failure. Trans Ophthalmol Soc UK 1973;93:601-9.

8. Allen KM, Berlin AJ, Levine HL. Intranasal endoscopic analysis of dacryocystorhinostomy failure. Ophthalmic Plast Reconstr Surg 1988;4:143.

9. Welham RAN, Wulc AE. Management of unsuccessful lacrimal surgery. Br J Ophthalmol 1987;4:152-7.

10. Walland MJ, Rose GE. Factors affecting the success rate of open lacrimal surgery. Br J Ophthalmol 1994;78:888.

11. Orcutt JC, Hillel A, Weymuller EA Jr. Endoscopic repair of failed dacryocystorhinostomy. Ophthalmic Plast Reconstr Surg 1990;6:197-202.

L. Chang

Wound Healing Research Unit

Department of Pathology and Glaucoma

Institute of Ophthalmology

London EC1V 9EL, UK

N. Trendell-Smith

Charing Cross Department of Histopathology

The Hammersmith Hospitals NHS Trust

London W6 8RF, UK

\section{J.M. Olver}

Department of Ophthalmology

Charing Cross Hospital

The Hammersmith Hospitals NHS Trust

Fulham Palace Road

London W6 8RF, UK

Tel: +44 (0)1818461497

Fax: +44 (0)1818461911

Sir,

\section{Microbial keratitis following cocaine abuse in a soft contact lens wearer}

Topical cocaine solutions have been shown to cause significant corneal epithelial damage. ${ }^{1}$ Indeed the association of microbial keratitis and corneal epithelial defects with crack cocaine is now well recognised..$^{2-4}$ We describe a soft daily wear disposable contact lens wearer who developed microbial keratitis associated with cocaine powder abuse. To the best of our knowledge this has not been reported before.

\section{Case report}

A 23-year-old woman presented with a 1-day history of an intensely painful red left eye. She had abused cocaine powder intranasally the previous night and accidentally administered it into her left eye, which she then rubbed vigorously. She also wore soft weekly disposable contact lenses on a daily basis for myopia. Chemical disinfection was used to clean her contact lenses, her pair at that time being only 1 day old.

On examination, corrected visual acuity with spectacles was $6 / 9$ in both eyes. The left conjunctiva showed marked hyperaemia and a moderate degree of

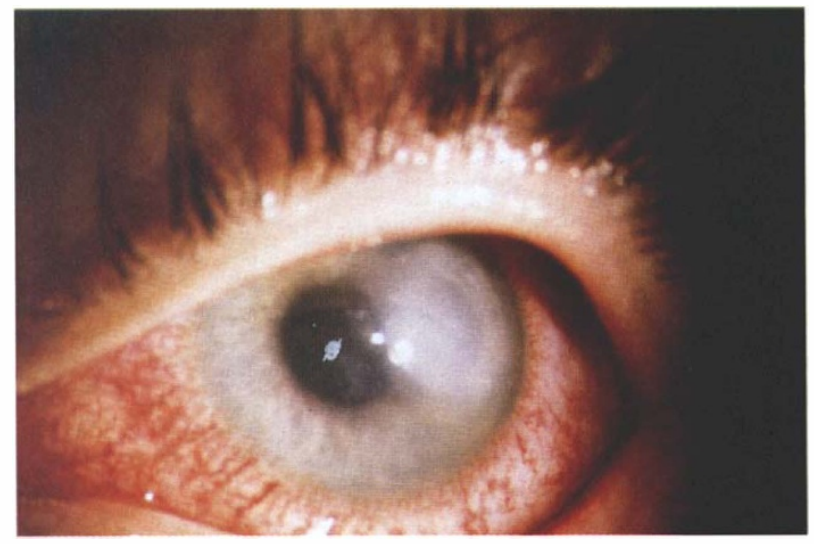

Fig. 1. Clinical appearance of the left cornea on presentation, showing stromal infiltrate.

fibrinous exudate. A left corneal ulcer measuring $3.5 \mathrm{~mm}$ $4.0 \mathrm{~mm}$ was present, with stromal infiltrates temporally in a semicircular configuration (Fig. 1). Corneal sensation was present, and there was a marked degree of cells and flare but no hypopyon. Corneal scrapings were immediately obtained for culture and Gram stain, the latter showing scanty pus cells and Gram-negative rods. The patient was admitted and treated with topical cefuroxime $5 \%$ and gentamicin forte $1.5 \%$ half-hourly, with atropine sulphate $1 \%$ three times a day. By day three, cultures yielded Pseudomonas aeruginosa, sensitive to ciprofloxacin and gentamicin. Topical cefuroxime was therefore discontinued and topical prednisolone sodium phosphate $0.5 \%$ commenced three times a day. She responded well to this treatment, and 5 days later tapering of topical gentamicin to 6-hourly was possible. Following 3 weeks of treatment she absconded from further follow-up visits, but finally attended after 5 months. A superficial left corneal stromal scar sparing the visual axis now remained with a visual acuity of $6 / 9$ in both eyes.

\section{Comment}

This report describes the presentation of microbial keratitis immediately following abuse of ocular cocaine powder in a soft contact lens wearer. Soft contact lens wear is well recognised as a predisposing factor for microbial keratitis. ${ }^{5}$ However, the rapidity of symptom onset following ocular contact with cocaine powder suggests it to have been a significant contributory factor in this patient.

Cocaine is directly toxic to corneal epithelium, causing disruption of intercellular spaces and epithelial cell motility complexes, leading to a reduction in corneal epithelium cell adhesion. ${ }^{1,3}$ The transient anaesthetic effect of cocaine would also have facilitated inadvertent rubbing of the eye, which would denude the corneal epithelium and predispose towards microbial keratitis. These effects would be further aggravated by mechanical trauma from contact lens wear.

The combination of soft contact lens wear with some or all of the above possible mechanisms related to the presence of cocaine in the eye may have led to the 
rapidity of microbial keratitis onset in this patient. We therefore suggest that specific inquiry regarding recreational drug abuse, including cocaine, should be made in any patient who presents with microbial keratitis.

\section{References}

1. Rossenwasser GOD, Holland S, Pflugfelder SC, et al. Topical anesthetic abuse. Ophthalmology 1990;97:967-72.

2. Strominger MB, Sachs R, Hersh PS. Microbial keratitis with crack cocaine. Arch Ophthalmol 1990;108:1672.

3. Sachs R, Zagelbaum BM, Hersh PS. Corneal complications associated with the use of crack cocaine. Ophthalmology 1993;100:187-91.

4. McHenry JG, Zeiter JH, Madion MP, Cowden JW. Corneal epithelial defects after smoking crack cocaine.

Am J Ophthalmol 1989;108:732.

5. Stapleton F, Dart JK, Minassian D. Risk factors with contact lens related suppurative keratitis., CLAO J 1993;19:204-10.

Dipak N. Parmar

Fiona Robinson

Paul A. Hunter

King's College Hospital

London SE5 9RS, UK

Dipak N. Parmar, BSC (Hons), FRCOphth

Chelsea \& Westminster Hospital

Fulham Road

London SW10 9NH, UK

Sir,

\section{Central serous chorioretinopathy in a patient with cryoglobulinaemia}

Cryoglobulinaemia has rarely been reported to cause ocular complications. Retinal vascular tortuousity and occlusions, cotton wool spots, retinal haemorrhages and uveitis have all been described in this disease. ${ }^{1}$ However, central serous chorioretinopathy (CSC) has been described in only two cryoglobulinaemia patients. We present a case of CSC and branch retinal vein occlusion (BRVO) occurring in a patient with hepatitis-C-induced cryoglobulinaemia.

\section{Case report}

A 36-year-old man was referred to our clinic for routine ophthalmic examination. He was known to have cryoglobulinaemia secondary to chronic active hepatitis $\mathrm{C}$ for the past 6 years. His ocular history was unremarkable. Among the systemic complications of this condition were leucocytoclastic cutaneous vasculitis, manifesting as recurrent bouts of non-thrombocytopenic palpable purpura on the legs. He later developed nephrotic syndrome, and a renal biopsy showed mesangiocapillary glomerulonephritis. Oral prednisone, $60 \mathrm{mg} /$ day, was therefore started, with significant reduction in proteinuria. Arterial hypertension was well controlled by atenolol, furosemide and hydrochlorothiazide, with values around $120 / 80 \mathrm{mmHg}$. He had mild normocytic normochromic anaemia. His serum glucose was $5 \mathrm{mmol} / \mathrm{l}$, the creatinine clearance was $60 \mathrm{ml} / \mathrm{min}$, total cholesterol was 2.6

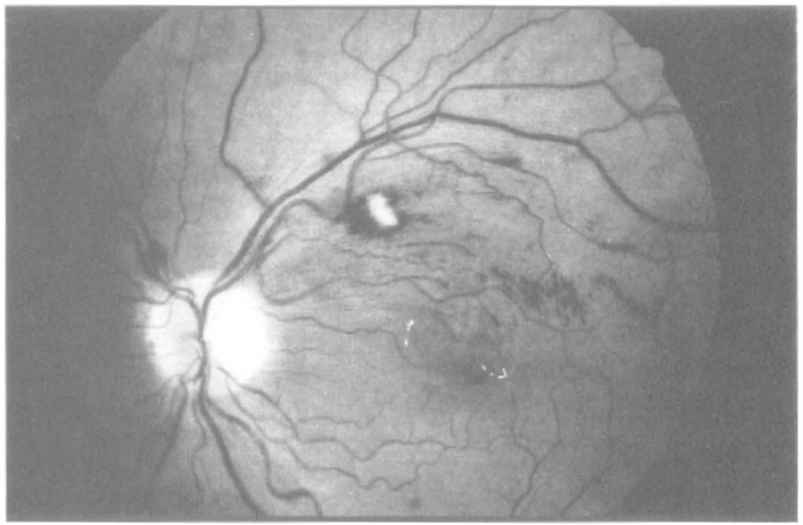

Fig. 1. A red-free photograph of the left fundus shows a superotemporal branch retinal vein occlusion with nerve fibre layer haemorrhages and a single cotton wool spot.

$\mathrm{mmol} / \mathrm{l}$. Liver function tests showed mildly increased hepatocellular indices, and a cholestatic disturbance, with alkaline phosphatase levels around $200 \mathrm{IU} / 1$ (normal up to $126 \mathrm{IU} / 1$ ) and gamma-GTP of $3000 \mathrm{IU} / 1$ (normal up to $76 \mathrm{IU} / 1$ ). Serum albumin was $41 \mathrm{~g} / 1$. Total serum bilirubin was $13 \mu \mathrm{mol} / 1$ with $7 \mu \mathrm{mol} / 1$ direct fraction. Plasma immune electrophoresis showed 10\% plasma cryoglobulin and an IgM kappa gammopathy. Hepatitis C virus RNA was found in his plasma by quantitative polymerase chain reaction in a titre of 186 copies $/ \mathrm{ml}$. Antinuclear factor and rheumatoid factor were negative; however, C3 complement level was $0.3 \mathrm{~g} /$ 1 (normal $0.71-1.56 \mathrm{~g} / \mathrm{l}$ ).

Upon examination, his visual acuity was $6 / 6$ in both eyes. Anterior segments were normal in both eyes. The retinal vessels were slightly congested and tortuous in both eyes. There was a superotemporal BRVO in the left fundus, without macular oedema or retinal neovascularisation (Fig. 1). During the following month the patient remained asymptomatic and the retinal haemorrhages gradually cleared.

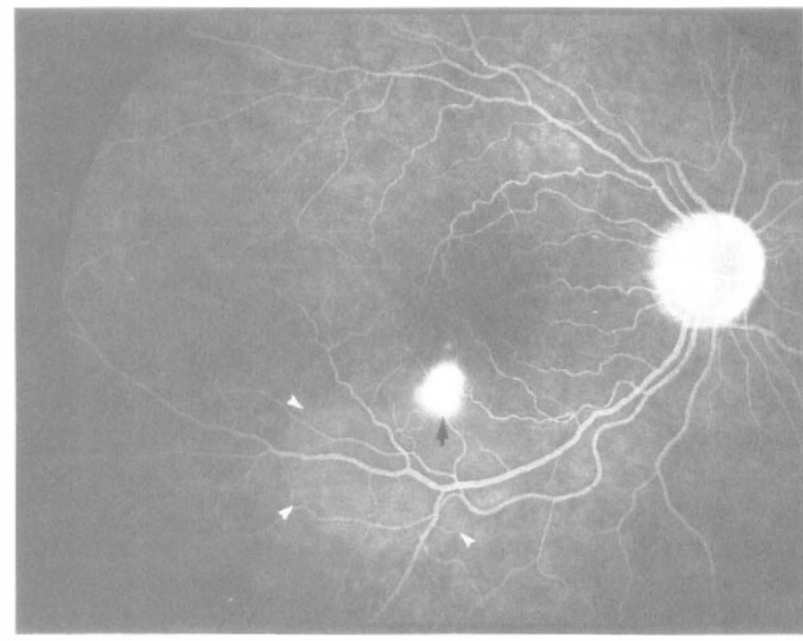

Fig. 2. A late-phase fluorescein angiogram of the right eye shows a typical central serous chorioretinopathy with serous retinal detachment (white arrowheads) and a focal leakage point (black arrow). 